\title{
Sexuality in subjects with intellectual disability: an educational intervention proposal for parents and counselors in developing countries
}

\author{
Gregorio Katz, MD,(1) Eduardo Lazcano-Ponce, MD, ScD. ${ }^{(2)}$
}

\begin{abstract}
Katz G, Lazcano-Ponce E. Sexuality in subjects with intellectual disability: an educational intervention proposal for parents and counselors in developing countries. Salud Publica Mex 2008;50 suppl 2:S239-S254.
\end{abstract}

\begin{abstract}
In developing countries, the study of intellectual disability has enormous knowledge gaps, especially in the areas of intervention, utilization of services and legislation. This article provides information not only for aiding in the potential development of sexuality in individuals with intellectual disability, but also for fostering their social integration. In Mexico and the region, in order to develop educational interventions for promoting sexual health, it is necessary to consider the following priorities:a) mental health professionals should have the knowledge or receive training for carrying out a sexual education and counseling program; b) educational interventions for subjects with intellectual disability should be adapted for the different stages of life (childhood, adolescence and adulthood); c) during childhood, educational intervention should emphasize the concept of public and private conducts; d) in adolescence, intervention should consider the actual mental age and not the chronological age of the subjects receiving intervention; e) the expression of sexuality in the adult with intellectual disability depends on the early incorporation of factors for promoting social inclusion; $f$ ) for educational interventions to be successful, it is fundamental that sexual educators and counselors, in addition to working with the clients, also work with their parents and other close family members; g) intervention programs should establish development objectives for developing in persons with intellectual disability a positive attitude towards sexuality and the improvement in self-esteem; h) in subjects with intellectual disability, their linguistic comprehension level should be taken into consideration and techniques for open discussion and non-induc-
\end{abstract}

Katz G, Lazcano-Ponce E.

La sexualidad en personas con discapacidad intelectual: una propuesta de intervención educacional para padres y consejeros en paises en desarrollo.

Salud Publica Mex 2008;50 supl 2:S239-S254.

\section{Resumen}

El estudio de la discapacidad intelectual presenta enormes lagunas de conocimiento en los países en desarrollo, sobre todo en las áreas de intervención, utilización de servicios y legislación. Este artículo proporciona información no sólo para contribuir al desarrollo potencial de la sexualidad en los individuos con discapacidad intelectual, sino también para impulsar su integración social. A fin de poder desarrollar intervenciones educativas para la promoción de la salud sexual en México y en la región, hay que considerar las siguientes prioridades: a) los profesionales de la salud mental deben tener los conocimientos o recibir capacitación a fin de poder llevar a cabo un programa de asesoramiento y educación sexual; b) las intervenciones educativas para los individuos con discapacidad intelectual deben estar adaptadas a las distintas etapas de la vida (infancia, adolescencia y edad adulta);c) durante la infancia, la intervención educativa debe enfatizar el concepto de conductas pública y privada; d) en la adolescencia, la intervención debe tomar en cuenta la edad mental real y no la edad cronológica de los individuos que reciben intervención; e) la expresión de la sexualidad en el adulto con discapacidad intelectual depende de la previa incorporación de factores promotores de inclusión social; f) para que las intervenciones educativas tengan éxito, es esencial que los educadores y asesores en lo sexual, además de trabajar con los clientes, trabajen también con sus padres y con otros miembros cercanos de la familia;g) los programas de intervención deben establecer objetivos de desarrollo para la creación de actitudes positivas hacia la sexualidad y una mejora en la autoestima de las personas con discapacidad

(I) Universidad Nacional Autónoma de México.

(2) Centro de Investigación en Salud Poblacional, Instituto Nacional de Salud Pública, México.

Accepted on: December 5, 2007

Address reprint requests to: Dr. Eduardo Lazcano. Instituto Nacional de Salud Pública. Av. Universidad 655, Col. Santa María Ahuacatitlán, Cuernavaca, México. Gregorio Katz. CADI. Hidalgo 7, col. Granjas de Guadalupe, Cuautitlán Izcalli, Estado de México, 54700 México. E-mail: elazcano@insp.mx,gkatzmina@prodigy.net.mx 
tive education should be used; i) social integration programs should address the needs of developing countries and their individuals, since it is not feasible to import external programs due to differences in infrastructure and the absence of public policies for promoting development; j) full sexuality in subjects with intellectual disability should be fostered in a comprehensive manner within an independent living program; $k$ ) in Mexico and the region, public policies should be instituted for administering independent living programs for people with intellectual disability and should lead to social, familial and economic power for the purpose of being productive. Thus, people with mental deficiency in developing countries can aspire to being integrated into social and work life and to appropriately expressing their sexuality.

Key words: intellectual disability; sexuality; health promotion; developing countries intelectual; $h$ ) en los individuos con discapacidad intelectual se debe tomar en cuenta su nivel de comprensión lingüística y se deben utilizar técnicas para discusión abierta así como educación no inductiva;i) los programas de integración social deben adecuarse a las necesidades de los países en desarrollo y sus individuos, ya que no es posible importar programas del exterior debido a las diferencias en infraestructura y a la ausencia de políticas públicas para promover el desarrollo; j) se deberá promover ampliamente una sexualidad integral en los individuos con discapacidad intelectual dentro de un programa de vida independiente; k) tanto en México como en la región deberán instaurarse políticas públicas para la administración de programas de vida independiente para personas con discapacidad intelectual que proporcionen el poder social, familiar y económico que les permita ser productivas. De esta manera las personas con deficiencias mentales en los países en desarrollo podrán aspirar a la integración social y laboral y a expresar apropiadamente su sexualidad.

Palabras clave: discapacidad intelectual; sexualidad; promoción de la salud; países en desarrollo
$F^{o}$ r many years, the focus on sexuality in individuals with intellectual disability (ID) exclusively centered on surgical sterilization, as part of programs in many developed countries. ${ }^{1}$ Nevertheless, a change in paradigms currently exists and, without considering some of the ethical and legal aspects that could be mentioned in relation to that practice, ${ }^{2}$ it is now necessary, 25 years after it had been instituted, to consider the need for promoting the sexual health of persons with intellectual disability from the public health perspective. ${ }^{3}$ This includes early sexual education, ${ }^{4}$ genital hygiene, ${ }^{5}$ prevention of unwanted pregnancies, ${ }^{6}$ prevention of sexually transmitted infections, ${ }^{7}$ as well as bringing an end to sexual abuse. ${ }^{8}$ This prospect cannot be established if substantive factors related to sexual development and the needs of individuals with intellectual disability are not known -from childhood, through adolescence and into adult life. ${ }^{9}$

This article emphasizes the sexual factors that counselors should consider throughout the life of subjects with intellectual disability. Accordingly, sexual education intervention programs during childhood should focus on outlining specific criteria for the development of public and private conducts, which should encompass the social environment of persons with intellectual disability and indicate all of the socially unacceptable or inappropriate behaviors -including sexual displays-in order to create an overall mental concept of behaviors that are acceptable to society. The adolescent with intellectual disability, as is the case for same-aged peers, tend to act impulsively and sexual displays are no exception.
Educational interventions, therefore, should focus on appropriately channeling their impulses so that they can satisfy the needs that correspond to that age. For the adult stage, considerations are made with respect to idiosyncrasy and the cultural context in which the adult is found, in addition to the benefits of fostering in persons with intellectual disability the possibility of establishing deep relationships (courtship); on occasion and under certain conditions, these relationships can culminate in marriage, while not overlooking the prevention of unwanted pregnancies and sexually transmitted infections, among other factors.

\section{The development of sexuality}

The development of sexuality begins from the moment the parents know the gender of their child and label them as male or female. Thus begins one of the most natural processes of creation; analyzed through the light of reason, it should not be an issue that causes conflict for human beings or discomfort for the parents when they transmit sexual education to their children. It is indisputable that, throughout time, sexuality has been one of the most controversial issues in the western world; consequently, it has provoked the emergence of different educational strategies and caused great difficulties for parents when explaining sexuality issues to their children.

Presently, in the Mexican population, the need for educational interventions for parents in order to foster the sexual health of adolescents has been established. ${ }^{10}$ 
Accordingly, if the incorporation of sexuality is controversial in this context, it is more so when linked with persons with intellectual disability. This population, given its complexity, represents one of the most extraordinary challenges for the mental health professional, since sexual education in these subjects and the development of socially appropriate sexual attitudes depend on the participation of parents, teachers and society as a whole.

The development of sexuality parallels the emotional and physical development of the persons; thus, entering adolescence, regardless of the mental age of the subjects with intellectual disabilities, they cannot help but notice that they have left childhood, and they need the support of the adult world to attain sexually acceptable behavior and to be appropriately integrated into society. In order for persons with mental deficiency to become adequately integrated into society, they must develop normalizing behaviors and attitudes in the area of sexuality and in all types of interactions: social, work and family. Therefore, in spite of sexual education, if the development in the areas mentioned above is not successful, it is impossible to meet the objectives outlined by mental health specialists when serving this population.

\section{General overview}

For society to endure, it is necessary to create norms and rules that enable it to work harmoniously in terms of the needs of all of the members of said society. One of the elements in which the norms may be more rigid is with respect to the display of sexual instincts; these, seen from a moral point of view, could be offensive if cultural, religious, educational and idiosyncratic factors are not taken into consideration. ${ }^{11}$

Communities have therefore developed rules that inhibit, restrict and confine the expression of sexual behavior, whose basic premises are described in table I.

Nevertheless, the needs of persons with intellectual disability are stigmatized when they are identified as subjects who are unable to express correct and responsible sexual development. Today, it is known that these individuals are able to properly express their sexuality within a context of respect, with behavior that is acceptable for their environment and in accordance with established norms, as long as they are given the necessary structure and sexual guidance. ${ }^{12}$ This requires an interactive process between the sociological perspective of the disability and the need for support and supervision, without losing sight of the different developmental levels, the intellectual limitations, adaptive behavior and acquired self-sufficiency skills.
Table I

BASIC PREMISES FOR THE EXPRESSION OF SEXUAL BEHAVIOR IN SUBJECTS WITH INTELLECTUAL DISABILITY

- Knowledge about displays that could be harmful or offensive for the individuals, in particular, or the society in general.

- Establishment of sexual behaviors that can be displayed in the privacy of a relationship.

- Developing an appropriate perception of sexual behaviors that are publicly acceptable.

It is essential to remember that persons who do not have any disability learn social behavior by the example of their role models, which fosters their sexual education. In addition, human tend to incorporate norms learned through lived experiences in similar situations, since they innately create a mental concept of what is socially correct and incorrect, acceptable and unacceptable; thus, behavior is generalized. On the other hand, persons with intellectual disability require, from infancy, a greater quantity of positive experiences and a continual systematization of their behavior for the development of such concepts, since the intellectual limitation blocks the generalization processes and, therefore, learning by imitation is restricted. ${ }^{13}$ If added to that cerebral damage that accompanies intellectual disability to various degrees and leads to greater difficulty in controlling impulses, it is understandable why the display of sexually or generally inappropriate behavior is more frequent in children with intellectual disability. ${ }^{14}$

As individuals with intellectual disability grow up and approach puberty, control over their behavior and the expression of their sexuality can take inappropriate turns and, when reaching adolescence or an adult age, aberrant or delinquent behavior can be observed, ${ }^{15}$ early intervention is therefore indispensable. On the other hand, affective deficiencies -common in this population- added to the intellectual limitation makes them easy pray for sexual abuse. ${ }^{16}$ Nevertheless, with adequate training that includes sexual education and counseling from the time they are young, it is possible to learn to channel their sexual impulses within social expectations; furthermore, such individuals can marry and fully experience sexuality with their partner.

Before delving into the issue of sexuality, it is useful to refer to programs dedicated to persons with mental deficiency, since it is not possible to conceive of healthy sexuality when other areas that allow the disabled individual to relate to and integrate into society have not been developed. In the best of cases, care for people with intellectual disability in Mexico has been limited to partial or total vigilance, whether it be in their houses or 
in institutions. As in many developed countries, more often than not the choice has been to protect them rather than promote the possibility of living in an autonomous and self-sufficient manner. ${ }^{17}$ This is why public policies must be encouraged for instituting independent living programs and providing the subjects with the possibility of attaining family, social and economic self-sufficiency. ${ }^{18}$

In these possible intervention centers, the emphasis in childhood should focus on stimulating cognitive skills through academic-practice areas and specific, comprehensive therapies in such a way as to obtain their maximum potential. These interventions support the elimination of aggressive and self-destructive behavior, develop an awareness of society and establish effective self-control for modulating inappropriate impulses. ${ }^{19}$ Such interventions, which have as their objective the integration of subjects with intellectual disability, focus their actions in the area of self-sufficiency -a requirement for later initiating prevocational and work programs. ${ }^{20}$ In adolescence, educational, social and work integration programs should put more emphasis on activities for assimilation into the community, the use of free time, household budgeting, personal care and work skills. ${ }^{21}$

In Mexico, one possibility is instituting an independent living program for the social and work integration of persons with intellectual disability, ${ }^{22}$ that fosters the comprehensive development of the sexuality of individuals with this disorder. Such a program includes providing competencies and skills to prepare the subjects for integration into "groups of belonging" and, ultimately, to live independently, under specialized supervision and without the need for overprotection by the family.

\section{The meaning of sexuality}

The concept of sexuality is an overall dimension that is socially and historically determined and entirely affects the whole person. Sexuality exists beginning at birth and actively intervenes in the development, evolution, emotional balance and affective stability of the person. It is of great importance in interpersonal relations and in couples' relationships. Therefore, it is not possible to separate sexuality from the rest of the personality. The principal objective for sexuality is pleasure and, therefore, human beings need to enjoy sexuality with their bodies in a comprehensive way, with their minds focused on obtaining and giving pleasure and with codes for relating to one another. This same phenomenon is also found in subjects with intellectual disability. People, in general, should learn to use their bodies in the way they like and in order to help them communicate for the purpose of their enjoyment. It is necessary to clarify that sexuality is not synonymous with sexual relations.

In this context, sexual education refers to the teaching of factors that are very important for the human being, such as friendship, courtship, marriage, parenthood and all type of relations -including sexual- while also taking into consideration sexually transmitted infections, birth control, pregnancy, family planning methods, personal and genital hygiene, among other factors. In addition, within an environment of tolerance and respect for the diverse concepts about sexuality that currently exist, socially acceptable behavior, as well as moral values, should be fostered in subjects with intellectual disability, in terms of their own autonomy; the final goal is for the individual to develop a sexual and social code for living. ${ }^{23}$

Individuals with intellectual disability are subject to the influence of three basic elements, as described in table II.

When the sexuality of persons with intellectual disability is considered, many questions emerge whenever it is incorrectly assumed that they also have a sexual abnormality. The physical or intellectual disability does not interfere in all cases with the healthy display of sexuality, unless their self-esteem is weak as a consequence of suffering continuous reflection from society. If added to this are alterations in the process of identification and difficulty in controlling impulses, it is understandable why conventionally unacceptable sexual behavior is so frequently observed in persons with intellectual disability. With the exception of these factors, disabled individuals can express their sexuality in an appropriate way and in accordance with societal standards.

\section{The sexual education of the therapist}

There are three educational factors that have been identified as being necessary for health professionals in

Table II

Social INFLUENCE ON SEXUAL EDUCATION FOR INDIVIDUALS WITH INTELLECTUAL DISABILITY

- Everyone is a sexual educator, although this fact is not fully recognized and people are subject to permanently transmitting and receiving different codes related to sexuality in daily life.

- Silence and evasiveness, with respect to aspects of sexuality, are signals that are as evident as acts.

- Teaching and sharing knowledge about sexuality fosters wellbeing and sexual health; on the other hand, silence and evasiveness leads to confusion, especially for subjects with intellectual disability. 
developed countries that are needed by professionals in the primary level of care for individuals with intellectual disability in developing countries: comorbility, interpersonal relations and sexuality. ${ }^{24}$ In this regard, to become a counselor on sexuality for normal individuals and persons with intellectual disability, it is necessary to understand and know about one's own sexuality. It is necessary to examine one's own life, feelings, attitudes and limitations. An effective counselor on sexuality must, in addition to knowledge, be aware of his or her own prejudices so that they do not interfere in the sexual development of the subjects receiving intervention. They also must be clear about their goals: teaching, questioning or sharing. It cannot be forgotten that students, with or without disabilities, are corrected and enhanced versions of one's self. If a sexual education program is initiated, it is indispensable to establish objectives and suggest diverse questions: Is the intention to eliminate sexual obsession or attenuate sexual interest? In ideal conditions, the goal is to develop in subjects with ID a positive attitude towards sexuality and an improvement in their self-esteem.

Professionals who work with disabilities (educators, psychologists, doctors, therapists, a variety of health professionals) are obliged to know their conceptual limitations, to be aware of the disadvantage that subjects with ID have with the abstraction of ideas and the development of the concept of sexual responsibility; as sexual counselors it is necessary to avoid injuring or hurting others. It is essential to foster early sexual health, impede pathological social behavior -such as the intention or possibility of being sexually violated ${ }^{25}$ and the prevention of subjects from becoming victims of any type of sexual abuse. ${ }^{26}$

When working with persons with intellectual disability, it is indispensable to recognize the linguistic comprehension level of these individuals; it is therefore essential to repeat the information several times, to give clear explanations and to confirm that the information does not create confusion. When necessary, an issue is analyzed in three or four different ways, until it is understood. The language used should be appropriate for their level and should frequently include idioms or colloquial words. The situation should be used as an opportunity for creating socially acceptable vocabulary. For example, "How many synonyms can you think of for the words penis, vagina or intercourse?" "Think of synonyms for hand, knee, elbow. It's not the same, is it?" Vulgar expressions with sexual connotations are used as expressions of aggression and reflect the most degrading language concepts. It is necessary to be aware that too much information can result in the individual not learning more; the conversation should be kept as clear as possible and the basic points should be repeated as often as necessary. Boredom, disinterest and confusion are signs of an excessive supply of information. It is also possible, without using too much information, to communicate it in a monotonous, technical or impersonal manner and, therefore, the students will react accordingly.

Sexuality should be looked at in a positive way and the discussion should be open and free of negative comments that cause guilt. ${ }^{27}$ A system for discussion is recommended, rather than a class, since this awakens the interest of subjects with intellectual disability, strengthens their learning and provides information that is as relevant as the data itself. In addition, the discussion should be based upon their principal interests and concerns.

The discussion should depend on the group's comprehension level and preparation. ${ }^{28}$ As is the case for children without intellectual disability, it is not possible to offer information for which the necessary chronological and emotional maturity does not exist. Some of the issues that should be taken into consideration in a sexual counseling program, and that provide space for the expression of responsible sexual behavior, are described in table III.

\section{Sexuality counseling during childhood}

From an early age, children display their feelings through their behavior, which occurs according to the emotional development level of each person. At first, the individuals notice that their behavior provokes a certain reaction from their parents and, as they mature, they understand that these behaviors affect a greater number

\section{Table III}

\section{A SEXUAL EDUCATION PROGRAM FOR SUBJECTS WITH INTELLECTUAL DISABILITY COMBINES BASIC TOPICS AND CONCEPTS}

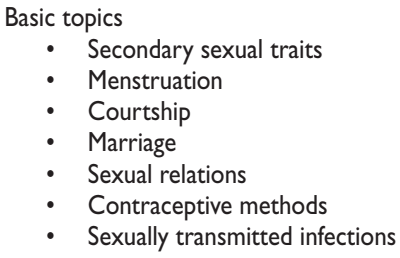


of people, and later, that they affect the whole society. Their behavior is thus formed and, as a consequence, the norms and rules of society are incorporated. When the parents incorrectly handle inappropriate behaviors, instead of eliminating them, they are reinforced and become more and more difficult to eradicate. In children with intellectual disability, because they do not have the same ability for generalization nor do they follow the same neurological and emotional development process, the assimilation of norms and rules takes place in a different manner and a specific way of handling it is required.

Due to the poor control of impulses and the low tolerance for frustration in children with intellectual disability, in addition to limited comprehension, these children, to lesser and greater degrees, tend to always search for gratification through pleasant sensations. When authority figures repress the search for these sensations, the child experiences this as though the only objective of these persons were to impede their experiencing pleasure. It takes a good deal of time for these children to understand that what they want is to prevent them from being injured or from hurting or offending society. It is therefore important to create a system of cause and effect, which should be characterized by consistency, firmness and clarity, and should not give double messages and, especially, not use physical and verbal aggression.

Within this system, which implies aspects inherent to sexuality, it is necessary to make the individuals aware that there are public and private conducts. The first ones do not offend or hurt anyone and, therefore, are accepted by society. For example, greeting someone, correctly approaching people, sitting with the legs together when wearing a dress, not lowering the pants except in the bathroom, being quiet, not yelling, among others. The second ones, which normal subjects learn easily, are an abstraction for people with intellectual disability. It is therefore necessary to counsel them not to burp in public, pass gases, pick the nose, scratch or touch their genitals, masturbate or take off their clothes in front of other people. As these children assimilate the concept of public and private, they will be able to differentiate sexual behavior from predominant social behavior. With the appearance of new behaviors, the counselor guides them and broadens their repertoire of behaviors. This allows the child (and later the adolescent and adult) to satisfy his or her needs without inhibiting them or offending others.

It is necessary to simultaneously deal with behavior that is more related to how and when (form) rather than why (content); kissing, hugging, caressing or playing, for example, are actions that are discussed with the child so that he or she develops responsibility with respect to impulse control. In addition, their moral judgment satisfies and leads to their respecting their body and those of others.

It is fundamental that the counselor remembers that the moral judgment of a child, unlike an adult, is in a process of formation and that, in the absence of the ability to rationalize orders, it is impossible to understand another's point of view. The result is that between two and seven years of age the child incorporates the moral and negative values of the parents without questioning, but from this moment on, they should be accepted based on conviction and not on imposition. These unquestioned moral precepts can become taboos. Adults must therefore be very careful when imposing their own moral judgments on their children. Due to this educational phenomenon, children with intellectual disability can use the system of public and private conduct with a great deal of success; however, as is the case with other children, it is necessary to be very careful so as not to impose mistaken concepts.

In order for this process to occur, it is essential for the counselor to work in parallel with the parents and other family members who participate in the education of these children, since they spend the majority of time with them. It is almost always at home where most of the inappropriate behavior occurs and, therefore, in order to eliminate it, the same sexual education program that is carried out at school must be continued at home. Thus, socially acceptable behavior is systematized and inappropriate behavior is eradicated.

Counseling parents requires a similar amount of time and effort as that which is dedicated to the children, since in addition to knowledge about sexual education, the parents should be counseled as to general ways for dealing with behavior and breaking the generalized taboos of the population..$^{29}$ It is of utmost importance to simultaneously help the parents overcome feelings of denial, rejection and grief; otherwise, it is impossible to avoid the emergence of emotional affectation observed in these children as a product of affective deficiency; this manifests itself through inappropriate, sexually aberrant behavior. When family problems interfere with the objectives of counseling, family therapy is needed; it should be remembered that the incidence of marital separation and divorce when there is a disabled child is statistically much higher than when this situation does not exist. ${ }^{30}$

\section{Sexuality counseling in adolescence}

With the beginning of puberty, a great amount of physical and mental changes arise in the normal adolescent. 
The first appearance of secondary sexual traits marks a corporal transformation that quickly leads to the child developing the body of an adolescent. This almost always provokes a state of anxiety because of not knowing how their body will look "in the end." Along with corporal changes, new intellectual processes are observed that allow the youngsters to begin the stage of formal operations. This enables them, on the cognitive level, to understand the experiences that they face. Nevertheless, it is very difficult for them to confront their emerging sexuality, the control of their sexual pulsions and the need to succumb to behavior that, although natural, overwhelms them (given that they are based on taboos) and inflicts doubt, uncertainty and insecurity.

In the adolescent with intellectual disability, the mental process is radically different. In relation to their own body, the same concern about the development of secondary sexual traits does not exist when they conceptualize the man and the woman only through their external appearance (image). With respect to cognitive processes, since they never get to the stage of formal operations, sexual pulsions are not questioned in conceptual terms. The basic problem is that, since self-control is not acquired, the behavior that emerges as a result of these pulsions can be acted upon with complete liberty, without any repression or feelings of guilt.

Thus, the importance of effective sexual education in childhood in these cases can be understood. ${ }^{31}$ If the incorporation of the concept of public and private conduct has been achieved -without attacking the child for displays of sexual curiosity and in terms of his or her need to express their sexual tensions (their behavior is oriented towards what is socially acceptable and unacceptable), as well as with the objective of preserving his or her self-image- the individual is prepared to confront the sexual processes that appear in adolescents with intellectual disability. Otherwise, therapy for these young people is much more complicated and requires a greater effort on the part of sexual counselors ${ }^{32}$ or their parents (a difficult situation to achieve), in order to later prevent painful experiences.

To illustrate these situations, it is possible to take the example of the parents of a girl who -in spite of seeing her pick her nose, sit with her legs open, seek caresses from everyone and approach adults inappropriately-is not corrected because it is taken for granted that these behaviors are normal in individuals such as she; but when they see her masturbate or touch her genitals they react violently and repressively, on occasion to the point of inflicting physical punishment and provoking a great deal of anger and rebellious reactions on her part, and attacking her self-image. It is important to remember that masturbation is a normal sexual expression that exists in all of the developmental stages of a human being and that its function is, in addition to seeking pleasure, the channeling of existing anxiety. This girl, who at first masturbated to satisfy a need, does not understand the reason for the aggression. This leads to her feeling rejected and she subconsciously discovers a "weapon" for controlling the aggressor; that is, she uses masturbation as a secondary gratification and is therefore inclined to masturbate in front of people in any threatening situation, no matter her age.

In those adolescents who did not receive adequate sexual counseling in childhood, the incorporation of concepts of public and private conduct ${ }^{33}$ is much more difficult to acquire. In this case, a humanistic behavioral therapeutic program is needed for dealing with "causes and effects" and for controlling, in time, their sexual impulses. Only after achieving this control, such subjects are ready for beginning sexual counseling that is appropriate for their stage of development -adolescence.

Once this social concept is incorporated, the adolescent with intellectual disability is prepared to receive both sexual education in accordance with his or her limitation as well as counseling for assuming the indispensable responsibility of understanding and expressing their sexuality. It is at this moment when such sexual education can begin, in which information is provided about anatomy. By then, everyone has a certain amount of information -almost always incomplete and distorted- especially with regard to those organs that are internal and, therefore, are not possible to verify. Just as it occurs for children without intellectual limitations, the starting point is based on previous knowledge from which it is possible to clarify and broaden the concept. As long as the individual does not have at his or her disposal basic information, the anticipated measures lack meaning. To overcome this limitation, it is necessary to work with small groups whose members have a similar level of information. When creating sexual education programs for adolescents, it is necessary to cover the basic areas detailed in table IV.

As can be observed, these areas are closely related with each other; consequently, it is possible to begin with that which is most beneficial according to the needs of each one of the students, and not necessarily follow this sequence. For its success, in addition to small and homogeneous groups, individualized programs are needed that take into consideration the needs of the youngsters with intellectual disability, those of their parents and, indirectly, the needs of society. These programs should include measures that take into account the linguistic and cognitive limitations of each subject in such a way as to maximize his or her comprehension. For example, if the student who receives counseling does not know 
Table IV

BASIC TOPICS FOR THE ADOLESCENT STAGE THAT SHOULD BE INCLUDED IN A SEXUAL EDUCATION PROGRAM FOR SUBJECTS WITH INTELLECTUAL DISABILITY

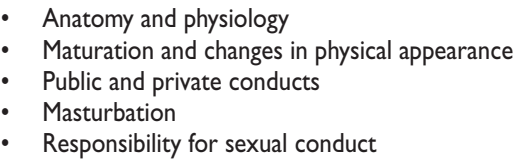

how to read, that student's program should include materials that do not require reading. These topics are described below in synopsis form, including essential, basic information for developing a sexual education and counseling program for adolescents with intellectual disability. It is worth noting that this should also be modified with respect to the level of intellectual limitation of the youngster or group.

\section{Anatomy and physiology of the reproductive apparatus}

It is necessary to first provide fundamental ideas about the sexual organs and their functions. Different methods are used to allow subjects with intellectual disability to identify the anatomical differences between men and women, since adolescents with intellectual disability often believe that both genders are the same. After understanding these differences, the basis for understanding many of the sexual processes is established.

Thus, the males also learn the female anatomy and the females, the male anatomy, so as to understand the differences between both genders. The following concepts can be emphasized: a) the same sexual organs always exist for each gender and b) these can vary in terms of shape, size and certain characteristics. In this context, it should be explained that the genitals are intimate parts and, therefore, should be dealt with privately.

From the beginning, one can take advantage of the opportunity to broaden their vocabulary and use appropriate terms. It is worth mentioning that the anatomy of persons with Down does not differ from other persons and their sexual organs have nearly the same proportions as the rest of the population. ${ }^{34} \mathrm{Nev}$ ertheless, the percentage of adolescents or adults with Down syndrome who are fertile is greatly reduced; ${ }^{35}$ as of today, less than 40 pregnancies in women with these types of chromosomal alterations have been reported.

\section{Maturation and changes in physical appearance}

It is possible to illustrate the corporal maturation process with colored drawings or anatomically correct dolls; each adolescent should identify with his or her own gender, recognize what his or her body is like at that moment, what it was like during childhood and how it will transform over time, and clarify any questions. In addition, this technique can be used for teaching selfcare methods. For girls, menstruation is described, as well as the use of deodorants, what to do about vaginal flow, genital cleanliness, removal of axillary and leg hair, among other elements of corporal hygiene. Another element that can be discussed with each girl is the appropriate use of a brassiere.

For boys, they are taught skills such as shaving, combing their hair, using deodorants and genital cleanliness, and are given information about erections -both night and regular erections- and night ejaculations, among other issues. It is also useful to discuss some of this information with adolescents of the opposite gender for the purpose of delineating the essential notions about the functions of the other gender. It is very important to talk about feelings and sensations that the corporal changes provoke with the intention of reducing the anxiety produced by some of these changes; as it is for all beings, it is important for them to know that the feelings and sensations are not correct or incorrect, but that they just exist and are part of the life of every person; what is important is to be responsible for these feelings just as they are responsible for controlling their behavior. The counselor should help the adolescent to find ways to appropriately channel such feelings, such as masturbation, which is discussed later.

\section{Public and private conduct}

This concept was covered at length in the section related to children's sexuality; therefore, this section will allude only to situations found in adolescence. In terms of public conduct, the development of skills should be continued regarding social adaptation, maturation of friendship relationships within groups of belonging and the identification of all non-sexual behavior.

This area is the most complicated to teach to subjects with intellectual disability, since it is the most abstract and, although it seems simple, it should aim to develop attitudes that take into account respect for other people in general and create a place in the world for belonging. It is indisputable that a large percentage of human beings do not find a place in society, which indicates that a 
certain intellectual quotient is not necessary, but rather, the possibility of satisfying affective needs in order to gain self-esteem. Although it is true that a considerable number of persons with intellectual disability have been victims of rejection by their parents, it is also true that, when joining a group of belonging, they can establish relationships and affectively relate with other persons like them and, consequently, feel that they matter. Fortunately, persons with intellectual disability need very little in order to be happy; when they are respected and accepted, belong to their group and are productive, their self-esteem is elevated and they develop the ability to respect others.

A moral code can be developed through a program for public and private conduct that allows them to accept the norms established by society and to incorporate the appropriate precepts from their cultural corpus. As one can imagine, if this self-esteem and societal respect is not attained, it is much more complicated to generate socially appropriate behavior; therefore, to avoid regrettable consequences, it is essential for them to incorporate social norms through a humanistic behavioral method, without neglecting to take into consideration the difficulty in carrying out any type of behavioral control during adolescence.

The social component of programs for public and private conduct is focused on the normalization of behavior during free-time activities, among them going to the movies, restaurants, parks, bowling, gatherings and dances. Thus, one can learn to differentiate, for example, where courting is appropriate and where it is not. The purpose of this area is for the person with intellectual disability to learn to generalize appropriate behaviors regardless of the particular place involved and to identify the places that are appropriate for carrying out public and private conduct.

\section{Masturbation}

This self-stimulation practice begins in infancy and continues into old age. Most people masturbate at some moment in their life and many do so throughout their life, whether they have a sexual partner or not. Periods exist when masturbation takes a prominent place in the life of a normal individual during certain stages (from 3 to 5 years old and in adolescence), stages during which individuals experience a great deal of anxiety which is liberated through genital self-stimulation. The less opportunity a person has to experience pleasure or the more they are inundated with anxiety or discomfort, the greater the tendency for relying on masturbation; it is therefore possible to deduce that, given that it involves a need, masturbation constitutes a right for all human beings, as long as it is carried out privately and does not offend anyone. Nevertheless, there are persons with moral or religious values who consider masturbation to be an unacceptable or abnormal practice. Parents or educators frequently have a determining influence over the upbringing of their children and they educate them and create taboos, feelings of guilt and conflict when, out of need, these youngsters rely on the habit of masturbating. Added to this group of people is a large number of individuals who, although they accept this activity as normal, they consider it unacceptable when concerning individuals with intellectual disability, just because subjects with disability should be asexual.

For adolescents with intellectual disability, masturbation is a resource used as frequently, or more, than any other adolescent, if you take into account that the opportunities that they have for satisfying their sexual gratification needs are more limited. The individual, therefore, should recognize that the manipulation of genitals is private conduct and that when doing it appropriately it is a normal process in adolescence that should not cause guilt. They also should know that this practice could bother many people around them. For some, they should be counseled in terms of how to do it in order to prevent them from hurting themselves, especially when using sharp objects. This is always carried out schematically, without causing shame, invading the privacy of the youngster or showing them personally (as some counselors do); the latter is solely a reflection of the counselor's pathology. ${ }^{36}$

It is important to encourage them to express the feelings that arise in relation to masturbation and help them control the negative sensations that frequently accompany this practice; nevertheless, those for whom masturbation causes conflict or whom prefer not to do it or not to talk about it need to be respected.

In the case of adolescents who excessively use masturbation and who, therefore, are not able to fulfill their activities program, it is essential to uncover the factors causing this excess and to help them control their anxiety in a constructive manner.

\section{Taking responsibility for sexual behavior}

This is the area of greatest controversy with respect to the sexual counseling of persons with intellectual disability, since all of the ethical and moral factors that intervene in this population of disabled beings come into play. It is undeniable that established sexual trends in many developed countries ${ }^{37}$ have influenced sexual counseling programs in some of these countries' institutions; culturally speaking, such programs are different. In fact, laws have been approved to protect citizens from 
sexual abuse by individuals who are capable of taking advantage of their positions of power. For example, the law on "consensual sex" states that mutual consent is necessary for establishing a sexual relationship between two adults. ${ }^{38}$ What happens when one of these individuals has a mental deficiency? It has already been mentioned that these persons never exceed the mental age of 12 , regardless of their chronological age. Should they be considered an adult in the case of giving consent? Are they prepared to assume the responsibility for the act that they are about to carry out? These are some of the considerations that should be taken into account with respect to persons with intellectual disability being responsible for their sexuality; this is discussed in greater detail in the section dedicated to adults. ${ }^{25}$

Everyone should be responsible for their own sexuality as well as their self-care. Therefore, in this area the counselor works with their clients regarding behaviors and consequences that are related with everything that is sexual. The primary method used for this is role-playing, which is discussed later, and creating situations in which persons with intellectual disability learn to assume responsibility for their sexuality. It should be remembered that it is common to find in individuals with intellectual disability obvious affective needs that they could try to compensate for through sexual experiences, when in reality they are only looking for affection. Since all sexual activities generate pleasant sensations, it is logical that the adolescent with intellectual disability will give into the desire and consent to participate in sexual types of activities, which creates the impression that their consent is due to a mature and responsible decision. ${ }^{39}$ In many liberal societies this leads to the subjects participating in very active sexual lives and this, consequently, leads to depression, loss of self-esteem and, very often, aggressive behavior. This is why it is important to dissuade clients from participating in sexual relations during adolescence; it is better to educate them to develop the responsibility of making a commitment, through courtship, that may later produce a stable relationship. In this area, subjects with sexual disability should learn to say no in any situation where it is required and to know to whom they can turn when they need help. ${ }^{40}$

Some concrete suggestions are presented below that can serve as guidelines for carrying out both a sexual education as well as a counseling program with adolescents. To begin the intervention, the counselor needs to conduct an evaluation of the current knowledge about sexuality, as well as skills that the individual has in this area. This should include at least two levels, that can be established more for the knowledge that the subject has and less for their chronological age; it is thus possible to identify if the person functions as an adolescent or if their interest is focused on the sexual activity of an adult. In general terms, throughout adolescence the person with intellectual disability does not show interest in sexual relations. On the contrary, given the uneven relationship between intellectual and physical maturity, their interest centers on friendship or courtship, similarly to how the normal adolescent begins their sexuality in early adolescence.

The success of a program depends on two basic components; the first consists of teaching the individual what he or she does not know, that is, providing him or her with the information necessary for filling the gaps in their knowledge, and then helping them to integrate this information in order to create in their daily life a functional pattern of sexually appropriate behaviors. To this end, all the persons involved in the education of the individual are counseled (parents, teachers, family members, work advisors, assistants, among others) so that they reinforce appropriate sexual behavior and all of the social elements related with their environment. The interdisciplinary team should take advantage of opportune moments for counseling the youngsters, situations that arise during daily activities. For example, greeting someone when appropriate, helping their friends, putting away their materials when finished with their work, respecting the emotional state of others, correctly expressing their sexual tensions within a public and private context, knowing how to correctly respond or asking for the help they need in situations of sexual abuse or mistreatment, relying on the counselor in accordance with the program and notifying him or her of inappropriate behavior on the part of any one of their friends or housemates, for the purpose of helping them acquire socially acceptable behavior patterns and for building their self-esteem.

The second component of the program consists of correcting inappropriate behavior, as well as their consequences, through role-playing (represention of behaviors), in which the counselor recreates the scenes (activities) where such behavior occurred. ${ }^{41}$ This technique, developed in a group context, consists of representing socially and sexually unacceptable situations for the purpose of objectively demonstrating the inappropriate behavior and offering, through a general discussion, alternative possibilities.

It is useful to remember that during this stage the adolescents' most frequent concerns have to do with the desire to have a boyfriend or girlfriend, a desire that is sparked by the need to imitate other young people or public figures with whom they identify. Gradually, the desires arise to kiss, hug, hold hands and talk on the phone. At first, this happens at all hours of the day 
and night and in front of everyone, without respect for schedules, activities or the opinion of others. To avoid this, it is very important to work with them on the concept of courtship, what it means and the responsibility that is involved in beginning a relationship. Through a commitment that is established with the partner they will be able to delay the need for immediate gratification, give up promiscuity and get prepared for a possible stable relationship, or perhaps future marriage in the end. Just by developing the sense of respect towards the boyfriend or girlfriend and by understanding the feelings that arise as a result of committing to be faithful, subjects with intellectual disability can become responsible for their sexual behavior. If not, it is possible that they end up as the type of persons with mental deficiency who put the search for gratification before their obligations and, for example, masturbate whenever they have the desire without taking into account the situation or the presence of other people.

The sexual behavior of the disabled adolescent being carried out within the guidelines imposed by society on any individual depends on adequately controlling sexual education and counseling; yet, even more importantly, only in this way is the individual prepared for beginning a sexual life in accordance with their real age and is assured that their limitations do not prevent them from establishing deep relationships that are necessary for achieving a good marriage.

\section{Sexual counseling for the adult}

Reaching adulthood with appropriate sexual behavior depends on all of the factors analyzed earlier. Nevertheless, although it is very difficult to imagine that an adult with intellectual disability can begin sexual education and counseling at that age, with the emergence in Mexico of centers that promote independent living for persons with intellectual disability, individuals who had not received any type of education have now begun to leave the seclusion of the family and have entered independent living programs, beginning their sexual counseling at that moment. Nevertheless, it has been observed that, when all of the available requisites are brought together, sexually acceptable behavior is feasible in the majority of the cases. This is achieved as long as the elements corresponding to the earlier stages are controlled, but without loosing sight of factors such as age differences, present behavior and prior experiences. Here, there is a break with the premise that the adult has already arrived at that point and therefore is prepared to begin the stage corresponding to sexual counseling.

Added to the areas analyzed in the adolescent are the topics described in table $\mathrm{V}$.

\section{The adult's responsibility regarding sexual behavior}

If what is intended by all educational programs is normalizing the behavior of persons with intellectual disability so that their behavior does not stand out among the rest of the individuals, this premise includes, without doubt, the area of sexuality. Therefore, the attempt should be made for the behavior of all intellectually disabled persons to be similar to that of the adult without limitations, always with the premise that what is not accepted of some, is not accepted of others. Nevertheless, it should not be forgotten that the maximum mental age that a person with intellectual disability can attain is 12 years; that is, before the stage of formal operations, a situation that makes it impossible to evaluate the risks that would be involved in a sexual relationship motivated by the search for pleasure; the need to help individuals make decisions can therefore be derived. Delineating behavior that is similar to that of adults does not necessarily presume the imitation of socially questionable behavior, as is often observed in people without disabilities, but rather behavior within the contexts determined by conventional societal values.

A diversity of regional programs currently exist that promote the concept of "people first", and its variations. ${ }^{42}$ This movement arose out of the necessity to respect disabled persons and offer them a place in society just like all other human beings. In addition, a fight exists for the same rights and privileges that all other individuals have, but without loosing sight of the fact that some of the limitations that subjects with intellectual disability have require fighting for their rights and protecting them, if the existence of their vulnerability is recognized.

It is necessary to understand that these rights come with the same obligations that all other citizens have; nevertheless, like others, persons with intellectual disability must earn these rights and it is the responsibility of the sexual counselor, as a consequence

Table V

\section{BASIC TOPICS IN THE ADULT STAGE TO BE INCLUDED IN SEXUAL EDUCATION PROGRAMS FOR SUBJECTS WITH INTELLECTUAL DISABILITY}

- Taking responsibility for sexual behavior

- Sexual activity with the same gender and the opposite gender

- Birth control

- Marriage and parenthood

- Sexual transmission of infections and their prevention

- Unacceptable and criminal sexual conduct 
of their educating their clients, that they attain the maturity needed for being responsible for their sexual conduct and being conscious of not hurting others and themselves. It should not be forgotten that the desire to lead a sexually active life is not the same as being economically, emotionally and educationally prepared to do so.

\section{Sexual activity with the same and the opposite gender}

Together, the situations mentioned -such as affective deficiency, the sole search for sexual pleasure and the denial of sexuality on the part of the parents of persons with intellectual disability- often have lead subjects with intellectual disability to sexually participate with persons of the same gender. This practice is observed especially in institutions (residences, hospitals, halfway houses, among other places) where persons of the same gender share the same bedroom. The "people first" movement justifies this practice on the basis that, as adults, they have the right to choose the sexual life that they want and the ability that intellectually normal adults have to choose. It is obviously not possible to discuss homosexual tendencies in these cases or that the decision to have sexual relations with persons of the same gender is the product of a comparative choice. Just as with intellectually normal persons, homosexual relationships could be a result of the inability to sexually relate with persons of the opposite gender or a comparative preference over previously unsatisfactory heterosexual experiences.

\section{Birth control}

One of the situations that most reflects societal taboos has been that of presuming that an individual's sexual activity begins with marriage. This provokes a heated debate between those who assume that talking about birth control with adolescents is the equivalent of encouraging premarital sexual activity and those who are of the opinion that, on the contrary, only through the sexual education of adolescents is it possible to avoid so many unwanted pregnancies and contracting sexually transmitted infections.

Although it is true that it is possible for persons with intellectual disability to marry, the reality is that a high number of them do not get married. Even so, it is undeniable that a large percentage of them will have sexual relations, which should not be surprising if the right to lead a responsible sexual life is recognized. In addition, it should be remembered that due to their intellectual limitation, the partner with intellectual disability is at a greater risk for pregnancy, which would complicate their emotional stability and that of their families. All sexual counseling programs should therefore emphasize teaching different contraception methods that guarantee that the woman does not get pregnant, for which it is essential to teach the use and risks of different contraceptive techniques that offer the greatest assurance (condoms, contraceptive pills and injections and intrauterine devices). It is also necessary to evaluate the use of sterilization techniques for men and women (vasectomy and salpingochlasia) as a permanent birth control alternative.

\section{Marriage and parenthood}

All marriages mark the end of one stage and the beginning of another and, although the concept of marriage is generally related to parenthood, when involving a partner with intellectual disability a series of questions arise: Does he or she have the ability to take responsibility for their own needs and those of another? Can they handle the economic challenges that marriage implies? Are they prepared to commit to being faithful? No doubt the answer is affirmative, as long as they receive adequate sexual education and counseling and have the support of an interdisciplinary team to help them with work and economic factors for achieving a selfsufficient life.

Persons with mild intellectual disability possess the ability to fully experience sexuality and share their joy, concerns and frustrations with a partner, as long as it does not put pressures and demands on them that weaken the stability of the relationship. One of the most common pressures is tied to these persons' economic situation when they do not have the support of their families; for example, economic subsidies granted in some developed countries that compensate disabled persons do not exist in Mexico.

Another common pressure in all marriages is that of the children. Even for persons with normal intelligence, children represent the greatest of responsibilities, as well as a source of constant concern. From birth, their wellbeing, happiness and expectations for their lives essentially depend on their parents, who must satisfy their physiological, affective, cognitive and emotional needs so that they attain their objectives. Children need to receive from their parents confidence, security, structure, and the possibility of positively identifying with them -both in terms of gender identification as well as 
with regard to their place in the community. Children need to receive from their parents the ego strength to confront the problems of daily life.

Those who are of the opinion that persons with intellectual disability meet the necessary requirements for parenthood need to analyze the characteristics of these persons; attributes can be considered such as nobility, simplicity, kindness, tenderness and the capacity to give affection, in such a way that it is possible to conclude that these attributes are not enough to give their children the ego strength or establish the structure necessary for the development of a healthy personality. In addition, experience from working with persons with mental deficiency demonstrates that these persons, due to their high social vulnerability and low tolerance for frustration, when faced with greatly stressful situations experience frequent regressions that make it impossible for them to make wise decisions, inasmuch as they often act impulsively.

Based on the experiences of parents of females with intellectual disability who have become pregnant because of poor counseling, sexual violation or abuse, it has been demonstrated that it is the parents who, in the end, take charge of raising the grandchildren. In such situations the feeling that the grandchild is the mother's toy is heightened, since she cannot comprehend or assume all of the obligations of raising a child. On the other hand, it is important to mention that the children of persons with intellectual disability can be born with intellectual disability, although the statistics show that, in spite of a slight increase in the number of births affected, this is not actually significant. Consequently, given that a large majority of these children possess normal intelligence or even higher than the population average, they are the ones who must confront the reality of having parents with intellectual disability. It seems that the group that fights for the rights of those with intellectual disability to have children forgets the rights of those children to grow up in a normal environment that makes their happiness possible.

To avoid the desire to have children, it is essential that subjects with intellectual disability work on their feelings, in the context of a sexual counseling program, until they comprehend their limitations in assuming the role of parenthood and take responsibility for choosing a birth control method that guarantees a marriage without children. At the same time, it is helpful that they identify all of the advantages of living with a partner and recognize that the procreation of children may be a way to imitate the family model -as occurs in the great majority of cases in which the motivation comes from the lack of knowledge as to what having a child implies.

\section{Sexually transmitted infections and their prevention}

Within the context of a sexual counseling program, it is important to work with clients about the risks of sexually transmitted diseases and how to protect themselves. Mentioning sexually transmitted infections by name was avoided for a long time, since this implied the practice of sexual relations without prevention. Nevertheless, the appearance of the AIDS virus and the elevated rate of the human papilloma virus and type 2 herpes has lead to reconsidering this concept and recognizing that the combination of both factors (promiscuity and disease) is real.

This situation has required the development of information campaigns for the general population, and especially for adolescents, so that they learn to have safe sexual relations, using the condom in particular ${ }^{43}$ as the only means that currently exists for avoiding infection.

When analyzing a sexual counseling program's plan, one of the requirements that stand out is related to the most important elements of "safe sex": having a stable sexual partner. This means that it is beneficial to help persons with intellectual disability develop the maturity to choose a partner before beginning sexual relations. Nevertheless, since this is not possible in all cases, they should be educated so that, in the first place, they learn to identify the symptoms of diseases; in the second place, they use condoms or abstinence in the event of the possibility of infection; and lastly, they recognize the appearance of signs and symptoms in themselves and where they can go to receive medical care. Because of the dangers that this area represents, it is essential for the counselor to verify that their students understood the information and that they are prepared to prevent any type of infection. ${ }^{44}$

\section{Unacceptable or criminal conducts}

This area is closely related to the concept of private conduct, as well as the norms and rules imposed in particular environments. In these cases individuals should know which sexual conducts are not conventionally accepted by society. Having intellectual disability is not a justification for acts of incest or sexual abuse or violation, since the appearance of these acts reflects poor or non-existent sexual counseling. As more people with intellectual disability receive sexual counseling, there will be less procedures in order to protect them from their actions.

Assimilating these norms is primarily carried out through cause and effect relationships and with the 
identification of each one of the actions with their consequences. The subject should take responsibility for his or her behavior and know the likely strict enforcement of the law. At the same time, moral aspects are explored so that, in the end, it is the spiritual, and not the legal, that leads them to behave in accordance with societal norms.

Another important element is the behavior that should be adopted when someone tries to sexually abuse them. Role-playing is used for this purpose; that is, the representation of possible situations and the way to act in such cases.

\section{Conclusions}

Society has established norms for its members to function in harmony; the area of sexuality is one of the most complex, since it involves cultural, religious, educational and idiosyncratic factors. Society therefore views sexual behavior in accordance with the premises described in table VI, which includes harmful and offensive behavior, those that are displayed in the privacy of a relationship and those that are publicly accepted.

The study of intellectual disability has enormous knowledge gaps, especially in the areas of intervention, utilization of services and legislation. This article provides information not only for supporting the potential development of subjects with intellectual disability and fostering their social integration -which constitutes a minimal action on the part of the State- but also for offering an organized social response in accordance to social, economic and health needs. This should not be a philanthropic activity but rather a public policy obligation. It is therefore necessary to consider the following factors for the possible optimal development of subjects with intellectual disability:

- So that individuals with intellectual disability can display their sexuality in accordance with social rules, it is essential that mental health professionals, as well as others who participate in their care, have the necessary knowledge or receive the training needed to establish a sexual education and counseling program.

Table VI

\section{Social PERCEPTION ABOUT SEXUAL beHAVIOR}

- Harmful and ofensive behavior

- Behavior displayed in the privacy of a relationship

- Publicly accepted behavior
- Educational interventions should be adjusted according to the different stages of life: childhood, adolescence and adulthood.

- During childhood, educational intervention should emphasize the concept of public and private conduct and enable the subject with intellectual disability to identify offensive behavior based on a system of causes and effects that allows the individual to control their impulses and thereby avoid the inappropriate display of sexuality.

- In adolescence, sexuality is expressed -just as with normal adolescents- through the characteristic sexual desires of puberty; it is necessary, however, to take into account that the adolescent with subnormal intelligence has a mental age equivalent to that of a child.

- The expression of sexuality in the adult with intellectual disability depends on the early incorporation of the factors that foster social inclusion. Unfortunately, when initiating a sexual education and orientation program at this age, the desired results are difficult to attain.

- For educational interventions to be successful, it is essential that sexual educators and counselors, in addition to working with their clients, also work with parents and other close family members.

- An intervention program should establish objectives for developing in persons with intellectual disability a positive attitude towards sexuality and improving their self-esteem.

- For subjects with intellectual disability, their linguistic comprehension level should be taken into account with techniques based on open discussion and not inductive teaching.

- Social integration programs should take into account the needs of developing countries and their individuals, since it is not feasible to import external programs given the difference in infrastructure and the absence of public policies that promote development.

- As persons with intellectual disability and their families receive sexual education and counseling, the behavior of these individuals will lead society to accept them and will grant them a place in the community, as well as enable them to become socially integrated and productive persons.

- The sexuality of subjects with intellectual disability represents an important part of their daily life. Nevertheless, if it is not complemented in a comprehensive way within the context of an independent living program, nearly all of them will be solely dysfunctional beings. 
- In Mexico and the region, public policies should be promoted for disseminating independent living programs for subjects with intellectual disability so that social, familiar and economic self-sufficiency becomes a real possibility and so that the individuals can, perhaps, be productive.

- Independent living models in groups of belonging exist where work training is received at the same time, until becoming ready for suitable work in the community.

- To guarantee the overall income of the group, sources of work must exist for everyone through a protected industry that absorbs them in the event that the community does not employ them.

Persons with mental deficiency can thus aspire to living in an integrated manner -both socially and in terms of work- and to appropriately expressing their sexuality.

\section{References}

I. Servais L, Leach R, Jacques D, Roussaux JP. Sterilization of intellectually disabled women. Eur Psychiatry 2004;19(7):428-432.

2. Stansfield AJ, Holland AJ, Clare IC. The sterilization of people with intellectual disabilities in England and Wales during the period 1988 to 1999.J Intellect Disabil Res 2007;5I (Pt 8):569-579.

3. Servais L. Sexual health care in persons with intellectual disabilities. Ment Retard Dev Disabil Res Rev 2006; 12(1):48-56.

4. McCabe MP, Cummins RA, Deeks AA. Construction and psychometric properties of sexuality scales: sex knowledge, experience, and needs scales for people with intellectual disabilities (SexKen-ID), people with physical disabilities (SexKen-PD), and the general population (SexKen-GP). Res Dev Disabil 1999;20(4):24I-254.

5. Eastgate G. Sex, consent and intellectual disability. Aust Fam Physician 2005;34(3): 163-166.

6. Leonard H, de Klerk N, Bourke J, Bower C. Maternal health in pregnancy and intellectual disability in the offspring: a population-based study. Ann Epidemiol 2006;16(6):448-454.

7. Clark LI, O'toole MS. Intellectual impairment and sexual health: information needs. Br J Nurs 2007; 16(3):154-156.

8. Michie AM, Lindsay WR, Martin V, Grieve A.A test of counterfeit deviance: a comparison of sexual knowledge in groups of sex offenders with intellectual disability and controls. Sex Abuse 2006; |8(3):27I-278. 9. Kennedy $\mathrm{CH}$, Niederbuhl J. Establishing criteria for sexual consent capacity.Am J Ment Retard 200I;106(6):503-510.

10. Gallegos EC, Villarruel AM, Gomez MV, Onofre DJ, Zhou Y. Research brief: sexual communication and knowledge among Mexican parents and their adolescent children. J Assoc Nurses AIDS Care 2007;18(2):28-34. I I. Rademakers J, Mouthaan I, de Neef M. Diversity in sexual health: problems and dilemmas. Eur J Contracept Reprod Health Care 2005; 10(4):207-2II.

12. Carrier S. Understanding social and professional integration as an adjustment process: contribution to a theory of coadaptation. Intellect Dev Disabil 2007;45(I): 10-22.
13. Piaget J.The essential Piaget. In: Gruber RE,Voneche J], editors. The language and thought of the child. New York: Basic Books, Inc. Publishers; 1977:85.

14. Stiers P,Vandenbussche E. The dissociation of perception and cognition in children with early brain damage. Brain Dev 2004;26(2):81-92.

I5. McDonald KE, Keys CB, Balcazar FE. Disability, race/ethnicity and gender: themes of cultural oppression, acts of individual resistance.Am J Community Psychol 2007;39(I-2):145-161.

16. Steptoe L, Lindsay WR, Forrest D, Power M. Quality of life and relationships in sex offenders with intellectual disability.J Intellect Dev Disabil 2006;3I(I):13-19.

17. Hatton C, Emerson E, Robertson J, Gregory N, Kessissoglou S, Walsh PN.The Resident Choice Scale: a measure to assess opportunities for self-determination in residential settings. J Intellect Disabil Res 2004;48(Pt 2): $103-113$

18. Wehmeyer ML, Bolding N. Enhanced self-determination of adults with intellectual disability as an outcome of moving to community-based work or living environments.J Intellect Disabil Res 200 I;45(Pt 5):37I-383.

19. Robertson J, Emerson E, Hatton C, Gregory N, Kessissoglou S, Hallam A,Walsh PN. Environmental opportunities and supports for exercising self-determination in community-based residential settings. Res Dev Disabil 200I;22(6):487-502.

20. Olsson MB, Hwang CP.Well-being, involvement in paid work and division of child-care in parents of children with intellectual disabilities in Sweden.J Intellect Disabil Res 2006;50(Pt I2):963-969.

21 . Fillary R, Pernice R. Social inclusion in workplaces where people with intellectual disabilities are employed: implications for supported employment professionals. Int J Rehabil Res 2006;29(I):3I-36. 22. Available at: www.cadi.org.mx.

23. Clark LI, O'toole MS. Intellectual impairment and sexual health: information needs. Br J Nurs 2007; 16(3): I54-156. 24. Phillips A, Morrison J, Davis RW. General practitioners' educational needs in intellectual disability health.J Intellect Disabil Res 2004;48(Pt 2): I $42-149$.

25. Parker T,Abramson PR. The law hath not been dead: Protecting adults with mental retardation from sexual abuse and violation of their sexual freedom. Ment Retard 1995;33(4):257-263.

26. McGrath RJ, Livingston JA, Falk G.A structured method of assessing dynamic risk factors among sexual abusers with intellectual disabilities. Am J Ment Retard 2007; I 2(3):22I-229.

27. Elkins TE, Kope S, Ghaziuddin M, Sorg C, Quint E. Integration of a sexuality counseling service into a reproductive health program for persons with mental retardation.J Pediatr Adolesc Gynecol 1997;10(I):24-27.

28. Baraitser P, Collander Brown K, Horne N. Community attitudes to the sexual behavior of young people in an urban area with high rates of sexual ill-health. J Fam Plann Reprod Health Care 2004;30(4):225-228.

29. Walter J. From taboo to self-actualization-acceptance problems and learning processes in working with mentally handicapped patients. Prax Kinder Kinderpsy 2002;5I (8):587-597.

30. Ellison D. Mental deficiency no ground for divorce. Lancet 1966;2(7477): 1358.

3I. Berman H, Harris D, Enright R, Gilpin M, Cathers T, Bukovy G. Sexuality and the adolescent with a physical disability: understandings and misunderstandings. Issues Compr Pediatr Nurs 1999;22(4): 183-196. 32. Fisher WW, Thompson RH, Hagopian LP, Bowman LG, Krug A. Facilitating tolerance of delayed reinforcement during functional communication training. Behav Modif 2000;24(I):3-29.

33. Birchall J. Coping with sexuality. Two. In a private place. Nurs Times 1984;80(50):3।-34.

34. Angelopoulou N, Souftas V, Sakadamis A, Matziari C, Papameletiou V, Mandroukas K. Gonadal function in young women with Down syndrome. Int J Gynaecol Obstet 1999;67(I):I5-2I. 
35. Bobrow M, Barby T, Hajianpour A, Maxwell D, Yau SC. Fertility in a male with trisomy 21.J Med Genet 1992;29(2): I4I.

36. Scott $\mathrm{H}$. Helping clients in their sexual expression. Br J Nurs 1998;7(10):568.

37. McConkey R, Ryan D. Experiences of staff in dealing with client sexuality in services for teenagers and adults with intellectual disability. J Intellect Disabil Res 200I;45(Pt I):83-87.

38. Spiecker B, Steutel J. Sex between people with "mental retardation": an ethical evaluation.J Moral Educ 2002;3I (2):155- 169.

39. Leicester M, Cooke P. Rights not restrictions for learning disabled adults: a response to Spiecker and Steutel.J Moral Educ 2002;3I (2):18I-187.

40. Martin R.A real life a real community: The empowerment and full participation of people with an intellectual disability in their community.J Intellect Dev Disabil 2006;3 I(2): I25-I27.

4I. Khemka I. Increasing independent decision-making skills of women with mental retardation in simulated interpersonal situations of abuse.Am J Ment Retard 2000; 105(5):387-40I.
42. Braddock D. Washington rises: Public financial support for intellectual disability in the United States, 1955-2004. Ment Retard Dev Disabil Res $\operatorname{Rev} 2007 ; 13(2): 169-177$

43. Bolu OO, Lindsey C, Kamb ML, Kent C, Zenilman J, Douglas JM, et al. Is HIV/sexually transmitted disease prevention counseling effective among vulnerable populations?: A subset analysis of data collected for a randomized, controlled trial evaluating counseling efficacy (Project RESPECT). Sex Transm Dis 2004;3I (8):469-474.

44. Gust DA, Wang SA, Grot J, Ransom R, Levine WC. National survey of sexual behavior and sexual behavior policies in facilities for individuals with mental retardation/developmental disabilities. Ment Retard 2003;4I(5):365-373. 